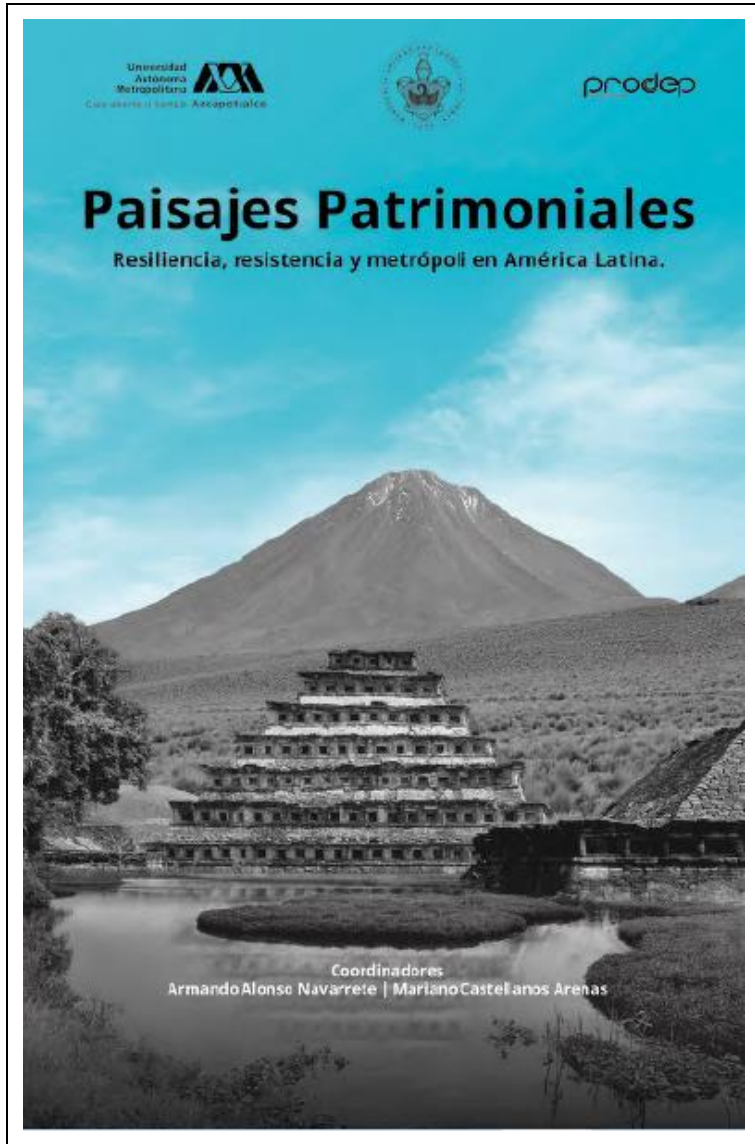

Checa-Artasu, Martín M. (2020).

ORCID: 0000-0002-6372-2938

Sunyer Martín, Pere (2020).

ORCID: 0000-0002-7383-2399

\title{
Las desventuras y reivindicaciones para un paisaje cultural. El caso del sistema hidroeléctrico de Necaxa, Puebla.
}

p. $180-206$

En:

Paisajes patrimoniales. Resiliencia, resistencia y metrópoli en América Latina. IV. Paisajes del agua / Armando Alonso Navarrete y Mariano Castellanos Arenas, coordinadores. Ciudad de México: Universidad Autónoma Metropolitana, Unidad Azcapotzalco, 2020.

Fuente: ISBN 978-607-28-1996-2 (versión electrónica). Relación: http://hdl.handle.net/11191/7575

\begin{tabular}{|c|c|c|}
\hline $\begin{array}{c}\begin{array}{r}\text { Universidad } \\
\text { Autónoma } \\
\text { Metropolitana }\end{array} \\
\text { Casa abierta al tiempo Azcapotzalco } \\
\text { Universidad Autónoma Metropolitana } \\
\text { Unidad Azcapotzalco } \\
\text { https://www.azc.uam.mx/ }\end{array}$ & $\begin{array}{l}\text { División de Ciencias y Artes para } \\
\text { el Diseño } \\
\text { https://www.cyad.online/uam/ }\end{array}$ & $\begin{array}{l}\begin{array}{c}\text { Departamento del Medio } \\
\text { Ambiente }\end{array} \\
\text { http://www.medioambiente.azc } \\
\text { uam.mx/iefatura.html }\end{array}$ \\
\hline & $\begin{array}{c}\text { Área de Investigación } \\
\text { Arquitectura del Paisaje } \\
\text { Área de Investigación } \\
\text { Arquitectura del Paisaje }\end{array}$ & \\
\hline
\end{tabular}

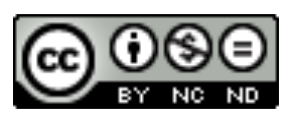

Excepto si se señala otra cosa, la licencia del ítem se describe como

Atribución-NoComercial-SinDerivadas

https://creativecommons.org/licenses/by-nc-nd/4.0/

D.R. (C) 2020. Universidad Autónoma Metropolitana, Unidad Azcapotzalco, División de Ciencias y Artes para el Diseño, Departamento del Medio Ambiente, Área de Investigación Arquitectura de Paisaje. Se autoriza copiar y redistribuir el material en cualquier medio o formato, siempre y cuando se den los créditos de manera adecuada, no puede hacer uso del material con propósitos comerciales, si remezcla, transforma o crea a partir del material, no podrá distribuir el material modificado. Para cualquier otro uso, se requiere autorización expresa del titular de los derechos patrimoniales. 


\title{
Las desventuras y reivindicaciones para un paisaje cultural. El caso del sistema hidroeléctrico de Necaxa, Puebla.
}

\author{
Martín M. Checa-Artasu \\ martinchecaartasu@gmail.com \\ Pere Sunyer Martín \\ peresunyer@live.com \\ Universidad Autónoma Metropolitana, Iztapalapa.
}

Resumen: Recientes aproximaciones teóricas en torno a los paisajes culturales están poniendo énfasis en su indudable valor para el rescate de la historia y el conocimiento de la evolución de los territorios. El paisaje cultural, en cuanto herramienta teórica es reivindicado como referente identitario y receptáculo que alberga la memoria de un grupo humano, de una sociedad, de un "pueblo", que lo ha vivido o lo sigue viviendo. En este sentido, el territorio culturalmente modelado sería la imagen especular de la forma cómo la sociedad se ha construido a sí misma. Sin embargo, los graves problemas derivados de la actual crisis ambiental, las limitaciones de gobernabilidad presentes en muchos ámbitos territoriales y los intereses depredadores del capitalismo imperante pueden, y, de hecho, lo consiguen, inhabilitar ese papel que pueden tener los paisajes culturales. Un ejemplo de ello es lo que acontece en lo que hemos denominado: paisaje cultural del Sistema hidroeléctrico de Necaxa (Puebla, México).

Palabras clave: Paisajes culturales, evolución territorial, Identidad, Gobernanza, Capitalismo.

Abstract: The new theoretical approaches about cultural landscapes have pointed out its value for historical recovering and for the knowledge of the evolution of territories. The cultural landscape, as theoretical tool is can show the identity signs and explain as a place that keeps the memory of a society and a community that still is living it. In this sense, the territory shaped by cultural elements is like a social mirror that reflects the way the society has built itself. Nevertheless, the consequences of the newly environmental crisis, the limits of governance in several regions, and the predator interests of capitalists are limiting this theoretical role of landscape. The analysis of Necaxa hydroelectric system in Puebla State, Mexico, as a cultural landscape is a good example of this kind of controversies.

Keywords: Cultural landscapes, territorial evolution, Identity, Governance, Capitalism. 


\section{Introducción.}

El Sistema hidroeléctrico de Necaxa está conformado por el conjunto de elementos e instalaciones para la generación de energía eléctrica que fueron construidas entre 1905 y 1954. Este sistema se inserta dentro del área de protección que se le otorgó, primero, en 1938 y, reconsiderado posteriormente, en 2002, con el nombre de Área de Protección de Recursos Naturales Zona Forestal Vedada "Cuenca Hidrográfica del Río Necaxa". Si en 1938 se protegió el papel estratégico para el abastecimiento de fluido eléctrico al centro del país, en 2002 se subraya su alto valor ecológico derivado tanto de los relictos de bosque mesófilo de montaña y de selva alta y mediana que aún conserva, como del sistema de humedales que se construyeron para la generación eléctrica. Finalmente, el conjunto del complejo hidroeléctrico y el área natural protegida se inserta en un entorno eminentemente rural, de honda cultura nahua reflejado en la perseverancia de la lengua, el uso de técnicas agrícolas y constructivas tradicionales y la presencia de lugares de resonancias míticas y religiosas (Chamoux, 1987; García, 2012; Peña Téllez, 2014; Ricárdez,2018).

Esta breve descripción nos habla ya de un espacio con personalidad en el que naturaleza, cultura tradicional y modernidad se entremezclan formando un espacio de gran interés que debe de conservarse y explicarse. Numerosos estudios han reivindicado el valor patrimonial tecnológico e histórico-industrial del sistema hidroeléctrico (García, 2012, 2017; Guadarrama y Páez, 2015; Martínez Miranda y Ramos, 2015a, 2015b; Montiel, 2008; Ortega, 2000; Peña, 2011, 2012; Romero, 2010, 2012) pero salvo alguna excepción, han dejado de lado el valor ecológico, ambiental y cultural que la propia construcción humana conllevó. Los abundantes elementos que se conservan revelan una parte no menospreciable de la historia del proceso de electrificación de México, plasmado en núcleos de población y casas-habitación, vías de comunicación y transporte, torres de transporte de la electricidad, aparte de los elementos técnicos que se conservan en las instalaciones hidroeléctricas, entre muchísimos otros. Asumir la presencia de tales elementos en un entorno particular del país es lo que permite caracterizar el complejo hidroeléctrico de Necaxa como un paisaje cultural; mismo que combina la presencia del agua asociada a un sistema de generación de energía eléctrica único en México, construido a lo largo de más de un siglo y con un enorme valor patrimonial; todo ello enmarcado en un área natural protegida, con distintos ecosistemas propios de esa zona geográfica y en un área de gran raigambre cultural.

Desafortunadamente, la notable complejidad de los problemas que se dan en la zona puede dejar indemne cualquier esfuerzo orientado hacia la consideración de todo este entorno como paisaje cultural y el 
mantenimiento del patrimonio construido. Se enfrentan ahí el grave deterioro ambiental de sus cuerpos de agua y de los ecosistemas por la presencia de núcleos poblacionales en crecimiento, los intereses múltiples para la explotación de los recursos naturales que la zona contiene y ofrece, y la crisis de gobernabilidad en distintos órdenes sociales con efectos en la economía local.

El texto que presentamos pretende justificar la necesidad de contemplar el ámbito donde se ubica el Sistema hidroeléctrico de Necaxa como paisaje cultural y mostrar la correlación de hechos que atestiguan los problemas que lo afectan y que pueden llegar a cuestionar tal consideración. Para ello, en primer lugar, daremos unos breves apuntes en relación con el concepto de "paisaje cultural" necesario para comprender la imperiosidad de aplicar una lectura integral del conjunto. Seguidamente describiremos someramente los elementos que lo conforman para finalmente centrarnos en los problemas que lo aquejan. Solucionarlos puede ser un paso para avanzar en su vindicación como paisaje cultural.

\section{El paisaje cultural: de concepto geográfico a patrimonial.}

El concepto de "paisaje cultural" es de aquellos que se ha visto afectado por un proceso de deriva semántica, desde un uso particular a otro vecino o, al menos, alejado del sentido original, pero que paradójicamente permite impulsar su difusión y popularización en otro contexto que el original. Así pasó con el término "ecología", "género" y tantos otros más que se usan ahora de forma un tanto alegre y sin atender a su origen. Algo parecido pasó con "paisaje cultural" cuyo significado y aplicación original en el ámbito de la geografía ha transmutado al que hoy se aplica en la evaluación del patrimonio de la humanidad en la UNESCO. En este sentido, cuando reivindicamos el complejo hidroeléctrico de Necaxa como paisaje cultural ¿a qué concepto estamos atendiendo, el geográfico o el de la UNESCO? o ¿a ambos a la vez?. Estas líneas pretenden dar respuesta a este aserto.

Fue en la geografía alemana de finales de siglo XIX que empezó a utilizarse el término Kulturlandschaft de la mano de Otto Schlüter, en cierta manera para distanciarse de los estudios corológicos o regionales de corte generalizador y analítico que propugnaban geógrafos como Alfred Hettner o Ferdinand von Richtofen. Para Schlüter, además de los elementos naturales, los aspectos culturales de la sociedad tenían su reflejo en las formas del entorno de manera que el paisaje resultante era la materialización de la acción histórica de la sociedad y de su cultura. De tal manera que si se atendía a la disposición de los objetos culturales sobre la superficie terrestre y los procesos tras de su presencia se podía conocer a la sociedad que sobre ella vivía. Así, Schlüter acuñó el término de "morfología del paisaje cultural" (morphologie der Kulturlandschaft) sobre 
todo para comprender los asentamientos humanos (Hofmeister, 2004), entendidos como una forma particular de paisaje.

El estudio del paisaje, de las formas terrestres culturalmente modeladas, venía a dar respuesta a otro de los problemas con que lidiaba la geografía humana, el de la correspondencia de la forma con la función y viceversa ${ }^{1}$. Como han reconocido algunos autores, la morfología del paisaje cultural era para la incipiente geografía humana lo que la geomorfología era para la geografía física (Whitehand, Larkham, 1992, p. 1).

Al mismo tiempo que Schlüter formulaba tales ideas, en la geografía francesa Vidal de la Blache asociaba el paisaje a las formas o modos de vida (genres de vie) de los habitantes de una región dada: leer el paisaje era entender esa forma especial de adaptación cultural del ser humano al medio que le rodeaba; y Jean Brunhes a través de la primera obra de geografía humana, titulada así, de la escuela geográfica francesa ( $L a$ géographie humaine. Essai de classification positive, 1910), incidía en los aspectos paisajísticos de la acción antrópica. De esta manera, casas, caminos, pueblos..., los elementos constructivos y creativos del ser humano son descritos admirablemente, así como su contraparte, los espacios producto de la destrucción humana del entorno. En cualquier caso, el paisaje era el resultado inequívoco del actuar humano sobre la tierra y el papel del geógrafo era identificarlos y explicar los procesos que les daban lugar.

Las ideas de Schlüter no tuvieron mucho eco fuera de Alemania. Fue a través Sigfried Passarge (1866-1958), Michael R.G. Conzen (1907-2000), o de geógrafos próximos a la cultura alemana, como Carl Sauer (1889-1975), que adquirieron mayor difusión, sobre todo, en el mundo anglosajón². Passarge amplió convirtió la morfología del paisaje en una ciencia tanto para estudiar los espacios naturales como los urbanos; Conzen lo haría para entender la morfología urbana, los asentamientos humanos, mientras que Sauer trasladó el concepto de paisaje cultural para la comprensión del mundo rural. Centrémonos en este último.

\section{El paisaje cultural de Sauer.}

Es a Carl Sauer (1889-1975) a quien debemos una parte nada despreciable de lo que hoy se entiende como "paisaje cultural". Fue con su obra The morphology of Landscape (1925) donde sintetizó muchas de las ideas de sus predecesores germanos y franceses.

1 Vease Sunyer, 2020. En publicación.

2 Sobre M.R.G. Conzen puede leerse la biografía de Terry Slater (2000) 
El paisaje era, según Sauer, para aquellos años del siglo $X X$, el área o la región. No era la escena pictórica, presumiblemente bella, a la que los artistas plásticos nos habían acostumbrado, sino la forma general del país, observada y descrita desde cualquier lugar. En su configuración intervenían los fenómenos naturales que le daban los rasgos principales (el marco geológico alterado por la acción meteórica y de las aguas superficiales) y del que surgían determinadas formas del relive, y la inevitable acción humana que a través del proceso de ocupación del espacio terrestre lo moldeaba con su cultura, su forma de comprender el mundo.

El paisaje cultural nacía en oposición al paisaje natural, supuestamente libre de la intervención antrópica. Cada grupo humano era el que definía, con su actuar cotidiano, un área cultural y asociado a él estaba el paisaje cultural. De esta manera, el estudio del paisaje permitía identificar áreas culturales y asociarlos a grupos culturales particulares. En este sentido, forma y función parecían llegar a una síntesis, una suerte de determinismo: "la cultura es el agente, el ambiente natural el medio, y el paisaje cultural el resultado" (Sauer, 1925, p. 343).

Llega así, Sauer al concepto de "personalidad", término con el que se refería a las formas de vida (genres de vie, de Vidal de la Blache) de aquellos grupos humanos de base territorial cuya acción histórica en el territorio conformaban sus respectivas áreas culturales. Su artículo "The personality of Mexico" (1941) alude al carácter de un país todavía con admirable presencia y fuerza de los grupos indígenas y en los que se podía estudiar, todavía, el estrecho vínculo entre sociedad, área cultural y paisaje cultural³

Los estudios morfogenéticos podían ser adecuados para entender espacios rurales, pero eran difíciles de aplicar a entornos urbanos en los que vivían numerosos y disímiles grupos humanos. Por ese motivo, al geógrafo formado en estas escuelas le costaba mucho trabajo aceptar términos como los de "paisaje urbano" y "paisaje industrial", por decir. Otras aproximaciones, como la funcionalista y la geográfico social, trataron de ahondar en aspectos no contemplados en este espacio contenedor al que se habían abocado los estudios del paisaje y superar el enfoque morfogenético con el que estaban asociados (Bobek, 1927; Bobek y Schmithüsen, 1949; Partzsch, 1964, en Ruppert y Schaffer, 1979). Empezaron a considerarse también los estudios sobre el comportamiento humano y a llamar la atención sobre las ideas de la sociedad sobre el espacio que construye -entre ellos el paisaje-y, más adelante a introducir perspectivas de corte humanístico, existencialista y fenomenológico, en los que la vivencia del entorno y la emotividad empezaron a ganar terreno. Ya

3 Ejemplos de esta asociación fueron los estudios de Robert Redfield sobre las "folkcommunities" de Tepoztlán (Morelos) y los pueblos de Yucatán. Véase Redfield, 1930 y 1933 
no interesaba tanto el contenido del paisaje, ni cómo era, si no lo que hacía con la sociedad, el paisaje como constructo social. El paisaje, lejos de ser un objeto, pasa a formar parte de la vivencia integral del individuo.

En este orden de cosas, en la UNESCO, en las reuniones del Comité del Patrimonio de la humanidad se empezaba a barajar en los años noventa la posibilidad de introducir una categoría intermedia entre los sitios de interés natural y los de interés cultural. Recibiría el nombre de "paisaje cultural".

\section{El paisaje cultural como bien patrimonial.}

En 1992, tras una reunión de expertos internacionales en la localidad francesa de La Petite Pierre, se propuso dar cabida a la nueva categoría de clasificación de los bienes de importancia mundial en la Guía operativa de implementación de la Convención del patrimonio de la humanidad, con el nombre de paisaje cultural ${ }^{4}$. Con la citada inclusión se hacía referencia a aquellos bienes "producto de la acción conjunta del hombre y la naturaleza", e "ilustrativos de la evolución humana y de sus asentamientos a lo largo de la historia". Se añadía además un componente de calidad, pues solo debían de protegerse a aquellos lugares que reunieran "valores universales excepcionales", representativos de regiones geográficoculturales específicas" (WH Committee, 1992; 1999, p. 36).

Con la mencionada declaración se dejaban de lado la mayor parte de los paisajes mundiales, cotidianos a la vida del ser humano, y ausentes de cualquier forma de protección ¿Dónde quedaba el paisaje cultural de los geógrafos?. Quedaba claro que una cosa era la reflexión teórica de delimitación de un objeto de estudio y otra la dimensión práctica que demandaba la Convención del patrimono de la Humanidad. Y así se vanagloriaba el Comité del Patrimonio de la Humanidad: consiguió llevar al terreno práctico "un término inusual [el paisaje cultural] para un concepto opaco" como era el del paisaje. Posteriormente se hacía una clasificación en tres grupos de los tipos de paisajes culturales que se distinguían ${ }^{5}$.

Son comprensibles los quebraderos de cabeza que la nueva categoría suscitó, y entender a su vez, el retraso de su aceptación. No se puede legislar sobre cosas etéreas y sin límites, por lo que el Comité del Patrimonio de la Humanidad requería de convertir el paisaje en un objeto discernible, identificable. Pero tampoco acabaría aquí la discusión. Una nueva vuelta de tuerca la vino a dar la aprobación del Convenio Europeo

4 Puede leerse para mayor información al respecto de lo acordado en el Comité del Patrimonio de la Humanidad en Sunyer (2017).

5 A saber: "Paisajes diseñados y creados intencionalmente por el ser humano; paisajes orgánicamente evolucionados, relictos o fósiles; y, Paisajes culturalmente asociadosvinculados a rutas, paisajes inmortalizados-." 
del Paisaje en 2000 y la celebración del $40^{\circ}$ anivesario de la Convención del Patrimono dela Humanidad. Ambas perspectivas volvieron a acercar el paisaje a sus dimensiones geográfico humanas, al reconocer la universalidad de los paisajes y de su valor cultural, y la necesidad de proteger a la sociedad que les da vida. Se recuperaba, nuevamente, de alguna manera, la vieja relación sociedad territorio que la geografía humana ha abordado tradicionalmente.

En su aplicación al caso que nos ocupa, el del complejo hidroeléctrico del río Necaxa entendido como paisaje cultural, su comprensión como tal precisa de la introducción de nuevos enfoques que permitan incorporar las diversas dimensiones que este lugar y obra de ingeniería contienen: las huellas de sus paisajes que se extienden espacialmente desde las tres pequeñas cuencas hidrográficas afectadas por la construcción del sistema hidroeléctrico hasta el entorno urbano de la ciudad de México; $y$, temporalmente, desde los primeros años del siglo XX hasta la actualidad.

\section{El paisaje cultural del Sistema hidroeléctrico de Necaxa: dimensiones de su complejo territorial.}

El Sistema hidroeléctrico de Necaxa viene marcado por su multidimensionalidad territorial. Nos referiremos a tres de ellas: su dimensión ecológica y ambiental; segunda su dimensión patrimonial, que hemos dividido en la cultural industrial y la cultural tradicional; finalmente, su dimensión geopolítica y geoestratégica.

\section{Dimensión ecológica y ambiental.}

El Sistema hidroeléctrico de Necaxa se alimenta principalmente de las aguas de dos subcuencas de los ríos Tecolutla y Cazones, la del río Necaxa y la del Laxaxalpan. Abarca una superficie total de 2,646 kilómetros cuadrados. La mayor parte del sistema fue protegido por decreto presidencial de 20 de octubre de 1938, por la que se creó la Zona Protectora Forestal Vedada de la "Cuenca Hidrográfica del Río Necaxa" (D.O.F. 20 de octubre, 1938) a iniciativa del ingeniero Miguel Ángel de Quevedo. Fue revalidada y actualizada a los criterios jurídico ambientales actuales por el acuerdo de 9 de septiembre de 2002 (D.O.F., 2002). Esta última adecuación fue solicitada por algunos operadores medioambientales que se movían en el área desde finales de los años noventa a través de entidades como Asociación Cañada de Patla y la Sociedad Mexicana de Lepidopterología. Ellos fueron quienes realizaron el proyecto y lo propusieron a la Comisión Nacional del Áreas Naturales protegidas (CONANP) (Ojeda y De la Maza, 2001). En 2013, atendiendo a la Ley General del Equilibrio Ecológico y la Protección al Ambiente (LGEEPA) se determinó que la extensión relativa al área natural protegida era de 41,973 hectáreas o 419.73 kilómetros cuadrados (ver Ilustración 1). Dentro 
de esa extensión se localizarían una parte importante de los elementos superficiales del Sistema hidroeléctrico de Necaxa (CONANP, 2013).

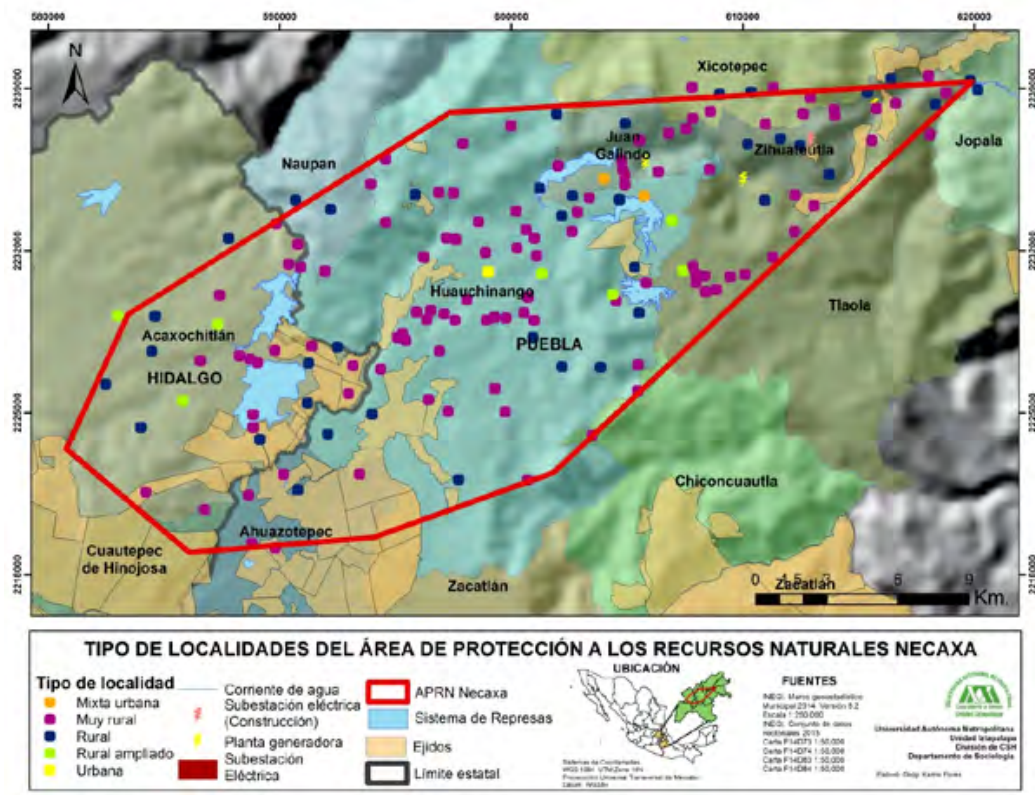

Ilustración 1. Polígono de la APRN Cuenca Hidrográfica del Río Necaxa.

Fuente: INEGI, 2014. Elaboración Karina Flores Cruz.

La relevancia de todo el conjunto había llevado a la Comisión Nacional para el Conocimiento y Uso de la Biodiversidad (CONABIO) en los años 80 a inscribir la mayor parte del sistema en dos regiones prioritarios, la Región hidrológica prioritaria $n^{\circ} 76$, río Tecolutla, y la Región terrestre prioritaria, $n^{\circ} 102$, Sierra Madre Oriental ${ }^{6}$. La primera de ellas reconocía la importacia del sistema lacustre artificial, ya naturalizado, del sistema hidroeléctrico como lugar de anidamiento de aves migratorias, mismo que permitió que en 2008 se incluyera tal valoración por la ONU al declararla sitio Ramsar "Sistema de Represas y Corredores Biológicos de la Cuenca Hidrográfica del Río Necaxa .

6 Actualmente, las Regiones prioritarias de CONABIO han pasado a ser Sitios prioritarios, Sitio prioritario terrestre para la zona de confluencia de los ríos Necaxa y Tenango y Sitio prioritario acuático epicontinental para las lagunas de Necaxa, Tenango, Nexapa y Los Reyes. Vale la pena añadir las cuencas hidrográficas de los ríos Cazones y Tecolutla forman parte de la Región Hidrológica 27 Tuxpan-Nautla. La subcuenca del río Necaxa se gestiona desde el Consejo de cuenca de los ríos Tuxpan al Jamapa, organismo dependiente del organismo Cuenca Centro de la Comisión Nacional del Agua (CONAGUA).

7 La certificación fue impulsada por la compañía Luz y Fuerza del Centro, sucesora de la Mexican Light and Power 
Desde el punto de vista ecosistémico, la APRN Cuenca Hidrográfica del Río Necaxa tiene diversos usos de suelo, así como, biotopos asociados. Se estima que el $47 \%$ de la superficie de la APRN se destina a agricultura de temporal siendo el maíz, café, algunos frutales y también ciertas plantas de ornato las cultivadas. Entre las superficies usadas por la agricultura hay escasos relictos de bosques. En torno al $48 \%$ está cubierto por bosques de pino, encino, pino-encino y mesófilo de montaña, así como por selva alta y mediana, subcaducifolia y subperennifolia, y pastizal ${ }^{8}$. El área, además, aglutina un centenar de especies de pteridófitas, algunas endémicas. En términos faunísticos también se localizan especies endémicas ${ }^{9}$.

\section{La dimensión patrimonial: el patrimonio cultural industrial del} Sistema hidroeléctrico de Necaxa.

Un hecho relevante en el territorio que estamos considerando es la presencia de un complejo de infraestructuras técnicas para la generación de energía eléctrica, construidas desde 1905 y adaptadas y mejoradas en distintos momentos hasta la actualidad. Éstas, dada su propia historicidad y su funcionalidad expresada en el paisaje, tienen un valor técnico e histórico muy relevante que les confieren un alto valor patrimonial, ampliamente reseñado pero que lamentablemente no tiene posibilidades de protección jurídica dada la normatividad actual (Ortega, 2000; Martínez y Ramos, 2005 y 2015; Montiel, 2008; Peña, 2011; Romero, 2010 y 2012; Alvarado, 2012; García, 2012, 2015 y 2017; Guadarrama y Páez. 2015; Checa et al., 2017; Checa y Sunyer, 2019).

Esa relevancia deviene por varios motivos. Fue el primer gran complejo hidroeléctrico que operó en América Latina que se vinculó a un sistema colectivo de transporte -el sistema tranviario de la ciudad de México, como parte del negocio eléctrico-y que además, concentró una actividad laboral especializada por más de un siglo. Fruto de ello es el todavía existente Sindicato Mexicano de Electricistas (SME), una organización emblemática de la historia del mundo laboral de México, con más de cien años de antigüedad, que ha liderado la lucha de los trabajadores del sector eléctrico.

El Sistema hidroeléctrico de Necaxa ejemplifica, asimismo, los cambios de la industria eléctrica del país: pasó de ser una inversión privada internacional a ser pseudonacionalizado en 1960 y gestionado por una

8 Entre éstas: el Sapo Pinero (Incilius occidentalis), Lili (Echeandia reflexa), Rana de Árbol Poblana (Plectrohyla charadricola), Tuza de Jalisco (Orthogeomys hispidus), Rana Manchada (Rana spectabilis), Hediondilla (Roldana lineolata), Culebra listonada de montaña Cola Larga (Thamnophis scalaris), Culebra encapuchada de Bocourt (Tantilla bocourti) y la Víbora cascabel transvolcánica (Crotalus triseriatus) que es una especie microendémica del APRN. Veáse: Bélgica et al, 2012

9 Cuenca Hidrográfica del Río Necaxa, Ficha SIMEC , 2016 
empresa semipública; fue extinguida por ley en 2009 para volver a ser concesionado a una sociedad privada donde el SME tiene una participación importante, lo cual hace de esa asociación un extraño ejemplo de cohabitación empresarial. Esa misma actividad laboral dejó huella en el territorio y por ende, en el paisaje a través de la conformación de un marco cultural, de elementos tangibles y mentalidades, observable en las localidades del entorno del sistema, especialmente, en Juan Galindo, basado en la actividad electricista y el sentido de pertenencia a la misma (Peña y Santander, 2017).

Comentábamos que el Sistema hidroeléctrico de Necaxa se caracteriza por la presencia en el paisaje de un complejo de infraestructuras técnicas tanto para el almacenamiento de agua, como para la generación de la energía eléctrica.

En relación con lo primero conviene señalar la intervención del ingeniero hidráulico Hugh Lincoln Cooper (1865-1937), verdadero artífice del diseño del conjunto (Dorn, 1979), capaz de vislumbrar la ubicación espacial de los distintos elementos que debían asegurar la disponibilidad anual de agua y su empleo en la generación de electricidad. También el ingeniero James D. Schuyler fue importante por su papel en la construcción de las presas que caracterizan el sistema hidroeléctrico: las presas de tierra por procedimiento hidráulico, que en aquellos años consiguieron almacenar un volumen de agua inimaginable hasta entonces que era sostenida por una de las presas más elevadas del mundo: el barraje de Necaxa es de 59 metros de altura por 350 metros de ancho de base y 360 de longitud de corona. Finalmente restan en la actualidad cinco grandes embalses que acopian el agua procedente de una vasta red interconectada de canales, túneles y sifones, presas de derivación de tres subcuencas de los ríos Tecolutla y Cazones. Este sistema regula las aguas en la época de lluvias y las almacena para los tiempos de sequía.

En la parte hidroeléctrica fueron instaladas inicialmente seis turbinas Escher Wyss, Co. tipo Pelton, de 8,200 HP con seis generadores SiemensSchuckert-Werke de 5,000 kW con posibilidad de obtener hasta 8,000 kW. Más adelante, se añadieron cuatro unidades más de 12,000 kW. Actualmente, la planta tiene diez generadores de corriente alterna, otra de las innovaciones del momento, capaces de enviar fluido eléctrico hasta 250 kilómetros de distancia del punto de generación (Pearson y Blackwell, 1907). Para esta transmisión se instalaron más de tres mil torres, las de tipo Necaxa, que, junto con su cableado para transportar la electricidad a una potencia de 60,000 volts, adornaron como nunca antes los campos mexicanos. De esa forma, todo el sistema hidroeléctrico se inscribió sobre una cultura y un paisaje subyacente de carácter rural y en el ámbito de las culturas nahua y totonaca, que todavía perviven. 


\section{Dimensión patrimonial intangible: la presencia de cultura indígena.}

El nuevo paisaje hidroeléctrico, si bien está conformado por las instalaciones del conjunto de este sistema, posee a manera de capas subyacentes el sustrato de otras secuencias culturales, algunas de mayor temporalidad y pervivencia. Nos referimos a la rica cultura nahua y totonaca, que aún hoy, tienen presencia en distintas partes de este territorio, expresada en diversas formas tanto tangibles (restos arqueológicos) como intangibles (rituales, topónimos, gastronomía, etc.) (Chamoux, 1987; Valencia y Mellado, 2005; Mora, 2011; Pérez, 2014; García, 2017). La misma construcción no estuvo exenta de la ritualidad necesaria para evitar que la profanación de espacios sagrados como cerros y ríos devinieran en males a quienes trabajaran en ellas (García, 2017).

Una de las preocupaciones de los pobladores manifiesta en los documentos de la Compañía Mexicana de Luz y Fuerza Motriz era que las obras respetasen los lugares de culto (las iglesias) y los cementerios (Checa et al. 2017). Así, a la localidad de Tenango se le protegió el espacio sagrado de la iglesia y el camposanto mediante una sorprendente corrección de la presa, mientras que otras poblaciones situadas en medio del valle -como tradicionalmente se hacía-se trasladaron las iglesias y los cementerios antes de la inundación.

La vida rural quedó completamente afectada. Las milpas, campos de naranjos y lugares de pasto de ganado que fueron descritos por el ingeniero Oropesa a principios del siglo $\mathrm{XX}$, quedaron cubiertas por las aguas (Oropesa, 1917-1920, p.212). Así aconteció con Necaxa, Santiago Patoltecoya y San Miguel Ocuautla, hoy bajo el embalse de Necaxa y cuyas nuevas poblaciones se hallan actualmente en sus orillas. Otras aldeas tuvieron que retirarse y dieron lugar a nuevas poblaciones, como Xaltepec, Papatlatla y Papatlazolco, situadas hoy a orillas de la presa Nexapa. Y mientras que esto sucedía, se crearon numerosos campamentos, muchos de ellos efímeros en los lugares de las obras; otros cedieron paso a las poblaciones actuales de Jacksonville y Canaditas.

La dimensión urbanística asociada a la construcción del sistema, así como las nuevas vías de comunicación incorporadas no se van a abordar en este artículo por falta de espacio, pero sí conviene resaltar la íntima vinculación del proyecto de Necaxa que las vías de comunicación (ferrocarril y carretera) y de transmisión de energía (cableado) propiciaban: las dimensiones geopolítica y geoestratégica, vigentes todavía tras el proyecto Necaxa. 


\section{Dimensión geopolítica y geoestratégica.}

Hay que señalar la última de las dimensiones que aquí vamos a considerar: la construcción del sistema hidoreléctrico de Necaxa forma parte del proyecto de modernización del Estado mexicano que se impulsaba desde el gobierno del general Porfirio Díaz. Como tal, es también un proyecto geopolítico y geoestratégico de consecuencias en aquel momento imprevisibles pues servía, además, para reafirmar la preponderancia de la capital de la República sobre las otras ciudades del país y contribuyó a asentar la industria también en el valle de México. El proceso de metropolización del territorio a partir de la ciudad de México que se inició en el siglo XVII (Sala, 1986) se volvió a acentuar con la hidroeléctrica. Finalmente, a partir de esta iniciativa también se construyó un espacio, en términos de Lefebvre, hasta aquel momento inexistente para los ciudadanos del centro del país, el de Necaxa.

Estas funciones geopolíticas y geoestratégicas se han manifestado en diversas ocasiones hasta la actualidad: así en 1938 con la promulgación de la Zona Protectora Forestal Vedada de la "Cuenca Hidrográfica del Río Necaxa", ya mencionada, se trataba de evitar el azolvamiento de los cinco embalses establecidos y asegurar el fluido eléctrico necesario para la capital ${ }^{10}$. No era concebible una parada de la dinámica capitalina.

También, durante el gobierno del general Cárdenas (1934-1940) se quiso utilizar el sindicato de la empresa Mexican Light and Power, el Sindicato Mexicano de Electricistas (SME), como ariete para golpear a las empresas privadas-entre ellas la susodicha-que no se avinieran a las proclamas de la Revolución y a su vez para allegarse a los trabajadores del SME como aliados frente a otros sindicatos ${ }^{11}$. Recordemos que la Compañía Mexicana de Luz y Fuerza sumistraba al centro del país el 80 por ciento de la electricidad por lo que a la presidencia de entonces no le interesaba estar supeditado al posible chantaje energético de esa empresa, ni tampoco al posible chantaje de sus trabajadores. La huelga de electricistas de julio de 1936 permitió al SME hacerse con el mejor contrato colectivo jamás conseguido en México, en cuanto a prestaciones y participación en los beneficios de la Mexican

10 Como ya se ha explicado en otra parte (Checa, Sunyer, Coello, 2017) el 9 de septiembre de 2002 se dictó un acuerdo por la que se revalidaba tal zona para convertirse en un área natural protegida de competencia federal, con la categoría de área de protección de recursos naturales con la denominación: Área de Protección de Recursos Naturales Zona Protectora Forestal Vedada "Cuenca Hidrográfica del Río Necaxa" (APRN Cuenca Hidrográfica del Río Necaxa) (D.O.F., 2002)

11 En Checa, Sunyer, Coello (2017) explicamos con cierto detalle el doble juego del presidente Cárdenas. 
Light and Power ${ }^{12}$. Este éxito permitió a la Compañía Mexicana conciliar con el SME ante una posible intervención del gobierno en el sentido de la nacionalización de la industria eléctrica, y al Sindicato esquivar la pretensión de Cárdenas de integrarlos en una organización vertical de electricistas, la Federación Nacional de Trabajadores de la Industria Eléctrica, precedente del Sindicato Nacional de Electricistas de la República Mexicana (SNESCRM) dentro de la cual estarían los trabajadores de la compañía eléctrica del gobierno, la Comisión Federal de Electricidad (Gómez-Tagle y Miquet, 1976, p. 162-163).

Las amenazas de nacionalización de la industria eléctrica persistieron durante los gobiernos que sucedieron a Cárdenas pero se hizo efectiva en 1960, con la presidencia de Adolfo López Mateos. También en la actualidad Necaxa está jugando otro papel geopolítico y geostratégico vinculado con la relevancia como espacio de interés naturalístico, para el desarrollo de proyectos turísticos, y de su principal recurso, el agua, para fuente de suministro para una ciudad sedienta, la capital de la República. Con ello se reafirma y acentúa el papel metropolizador de la ciudad de México. Sin embargo, reclamar tal protagonismo ha de pasar por solucionar algunos de sus problemas.

\section{Los graves problemas ambientales del Sistema hidroeléctrico de Necaxa.}

Como ya hemos señalado el Sistema hidroeléctrico de Necaxa se integra dentro de un área más amplia que goza de protección ambiental determinada en sendos decretos de 1938 y 2002. Ello ha hecho que en los últimos 15 años el territorio del sistema hidroeléctrico, a la vez que el territorio del área natural protegida haya sido objeto de distintos tipos de análisis, especialmente, los relacionados con sus problemas ambientales. A día de hoy, rubros como la calidad de agua en embalses y canales, el vertido de aguas residuales de las localidades adyacentes y el deterioro producido por las crecidas y fenómenos meteorológicos de gran intensidad, los problemas de la deforestación y los movimientos de remoción en masa en laderas y pendientes (deslaves) son algunos de los más preocupantes. Se trata de una situación que tiene al menos tres lustros como demuestran diversos trabajos. El primero de ellos es el diagnóstico del sistema hidrológico que se realizó entre 2000 y el 2001 por iniciativa de Luz y Fuerza del Centro, empresa que operaba las plantas eléctricas del Sistema hidroeléctrico de Necaxa, con la colaboración de la Comisión Nacional del Agua (CONAGUA), el gobierno del Estado de Puebla

12 El contrato colectivo vencía en 30 de abril de 1936 y la huelga estalló en 16 de julio de ese año. Véase también Campos Vega, 2014. Comunicación Personal de Antonio Guadarrama y José Coello, 2015 (CODEPACUTI, Comité para la Defensa del Patrimonio Cultural, Tecnológico e Industrial, sector Eléctrico) 
y el Instituto de ingeniería de la Universidad Nacional Autónoma de México (UNAM) (Luz y Fuerza, 2000). El mencionado estudio instó a diseñar un plan de saneamiento de la cuenca del Necaxa ya que en ese entonces se habían detectado problemas como los de descargas de aguas residuales en los ríos, la existencia de tiraderos de basura al aire libre o de rellenos sanitarios manejados de manera incorrecta, la erosión y deforestación y la presencia de riesgos en zonas geológicamente inestables (Barrios et al. 2002). En 2003 se llevó a cabo el Estudio de ordenamiento ecológico territorial de las cuencas hidrológicas de los ríos Necaxa y Laxaxalpan, instado desde Secretaria de Medio Ambiente y Recursos Naturales y desarrollado por el Instituto Nacional de Ecología y la Universidad Autónoma Chapingo. En él se recogía la situación y dinámicas ambientales de ambas cuencas hidrológicas, caracterizadas por el aumento del uso de suelo para actividades humanas, la deforestación, el vertido de residuos sólidos al aire libre y de aguas negras a los cursos y cuerpos de agua y la presencia de áreas con riesgo geológico alto y medio en distintas zonas. Las conclusiones de este trabajo, similares a las que se diagnosticaron en el informe del Instituto de Ingeniería de la UNAM de 2001, instaban a usar el ordenamiento ecológico territorial como una herramienta de diagnóstico e implementación de políticas de saneamiento de la zona y de conciliación entre los usos humanos y el medioambiente (UACHA, INECOL, 2003).

En febrero de 2007 se celebraba en la Cámara de Diputados el Foro sobre el desarrollo integral de la Cuenca de Necaxa, convocado por la Comisión de Medio Ambiente y Recursos Naturales de la Cámara de Diputados, LX Legislatura. En dicho foro se explicitan las acciones realizadas y las que se deberían realizar, así como posibles acciones para el saneamiento, protección ambiental y desarrollo productivo de la zona (Cámara de Diputados, 2007). Dicho foro, organizado por actores políticos con intereses en el área pero también, gracias a las demandas de la sociedad civil organizada, revelaba que los problemas de gestión del área natural protegida y por ende, del Sistema hidroeléctrico de Necaxa no sólo persistían sino que se habían acrecentado y complejizado. Un año más tarde, 2008, el APRN Cuenca Hidrográfica del Río Necaxa obtenía la certificación RAMSAR que la reconocía como un "Humedal de Importancia Internacional (Flores, 2008), bajo la denominación: Sitio RAMSAR “Sistema de Represas y Corredores Biológicos de la Cuenca Hidrográfica del Río Necaxa. Dicha certificación se obtuvo gracias a la intervención e interés de Luz y Fuerza del Centro, la empresa operadora del Sistema Eléctrico. Llama esto la atención al tratarse de instalaciones construidas por el hombre a principios del siglo XX y que se han integrado en el contexto medioambiental de la zona. De alguna manera, con esta nominación se pretendía llamar la atención de la importancia del lugar y el estado ambiental del mismo a las autoridades federales y estatales que hasta la fecha habían hecho caso omiso. 
A partir del decreto de extinción de la empresa Luz y Fuerza del Centro, de octubre de 2009, los problemas ambientales de la zona se acrecentaron por olvido e indolencia. Desde ese momento, a los problemas territoriales y ambientales se añadía el problema social y laboral: se despidieron de la noche a la mañana, más de 40.000 trabajadores, entre estos los que operaban el Sistema hidroeléctrico de Necaxa.

Pese a los pronunciamientos y esfuerzos realizados para señalar los problemas que en términos ambientales se dan en el Área de Protección de Recursos Naturales Zona Forestal Vedada Cuenca Hidrográfica del Río Necaxa, a día de hoy, la misma no cuenta con un plan de manejo publicado y operativo ${ }^{13}$. Desde 2008 se viene discutiendo tanto un plan de manejo para la APRN Cuenca Hidrográfica del Río Necaxa como la modificación de la extensión de la misma por parte de la CONANP y diversos agentes políticos han reclamando el mismo (Senado, 2013, p.4). La inexistencia de un Plan de manejo ha sido denunciada ya por la Comisión Nacional de los Derechos Humanos (CNDH) en su recomendación general sobre temas ambientales 26/2016.

Con todo, desde 2009 en el área la dirección de la APRN Cuenca Hidrográfica del Río Necaxa se han realizado algunas acciones como son programas de reforestación limitados en distintos lugares y acciones de prevención frente a un incendio forestal (UACHA, INECOL, 2003; CONANP, 2011; Niembro, 2014). Posteriormente, en 2012 se realizó un análisis del cambio de cobertura forestal en la ANPR, dentro de un proyecto patrocinado por la CONANP y la Deutsche Gesellschaft für Internationale Zusammenarbeit (GIZ) que demostró una Tasa de Transformación de las Cubiertas Forestales para la APRN era del 0,1\% anual lo que indicaba que cada año perdía 23 hectáreas de masa forestal (Ríos, 2012).

La inexistencia de un plan de manejo atribuible con toda probabilidad a los intereses de grupos de poder de la zona, aunado al desinterés de las autoridades federales responsables del área, ha hecho que se acentúen los problemas antes reseñados, que han sido documentados puntualmente por la prensa local, como la permisibilidad ilegal de ciertas obras en el interior de la APRN; la aceptación de ciertos cambios de uso del suelo; el permiso de construcción del relleno sanitario de alta compactación en Nopala, en el municipio de Huauchinango, propiedad de Inmobiliaria Tierra Mexicana; la tala ilegal en el bosque de la comunidad de Teopancingo; las afectaciones

13 Desde el 1 de julio de 2014 es director de la APRN el biólogo Elimelec Anzures Vázquez, egresado de la Universidad Autónoma del Estado de Morelos, responsable que el plan de manejo para la ANPR sea publicado y se realice. Anteriormente, desde 2009 ocupó el cargo la arqueóloga Silvia Niembro Rocas quién al parecer hizo caso omiso a la redacción y publicación de dicho plan. Al parecer, existe un borrador de plan de manejo que está siendo utilizado sin el aval aprobatorio correspondiente y que de forma oficiosa es el que sirve de marco de actuación en esa área natural. 
por la cercana construcción de la autopista México-Tuxpan, a pesar de la recomendaciones de la manifestaciones ambientales realizadas; el vaciado de desechos de asfalto de esa obra en la presa de Tenango de las Flores y los vertidos al aire libre en la barranca de El Zoquital en Xicotepec (Ramírez, 2014; Ánimas, 2014b).

Desde el Consejo de cuenca de los ríos Tuxpan al Jamapa, organismo que gestiona las aguas de la subcuenca del río Necaxa, mismas que transitan por el Sistema hidroeléctrico, se han realizado algunas acciones, aunque limitadas. Desde 2007 se creó un Grupo Especializado de Saneamiento del Río Necaxa (GES) compuesto por personas seleccionadas por parte del gobierno del estado de Puebla y la CONAGUA. Se trata de un organismo auxiliar del Consejo de cuenca de los ríos Tuxpan al Jamapa, ente creado el 12 de septiembre de 2000 . Tras un largo periodo de inactividad se reactivó el GES Río Necaxa en abril de 2014 tras reunión celebrada en el municipio de Huauchinago. La aspiración de este grupo era convertirse en una comisión de cuenca que atendiera los problemas de esa cuenca hidrológica. Éstas se centraron en las formas de captación de aguas y en mitigar el vertido de aguas negras y el saneamiento de las mismas. El mencionado GES realizó en 2014 un diagnóstico de las acciones de saneamiento realizadas entre 2001 y 2013 y propuso un programa de trabajo para el 2014 (Consejo de Cuenca, 2015). Desde esta instancia se encargó a investigadores de El Colegio de Veracruz la realización de Programa para la gestión integral de la subcuenca del río Necaxa que delinea una serie de acciones vinculadas con el plan hidrológico nacional 2014-2018 como son: establecer acuerdos o convenios intermunicipales que se orienten a la conservación del ecosistema de la cuenca; rescatar la infraestructura hidroeléctrica del Sistema Necaxa para la generación de energía eléctrica; innovar la gestión de los residuos sólidos municipales; contar con información actualizada sobre la disponibilidad de agua en la subcuenca e incentivar actividades agroforestales y forestales para conservar los suelos sobre todo en los municipios de la parte media de la subcuenca: Tlaola, Huauchinango, Juan Galindo y Xicotepec (Ruelas et al. 2016). Sin embargo, a pesar de dicho proyecto, a la fecha no se observan resultados tangibles en el área.

\section{La explotación del agua y el turismo ¿Nuevos intereses en el Sistema Hidroeléctrico de Necaxa?}

La extinción de Luz y Fuerza del Centro (LyFC) en 2009 llevó no sólo al paro técnico de las instalaciones del Sistema hidroeléctrico de Necaxa y su cesión a la otra empresa pública eléctrica mexicana, la Comisión Federal de Electricidad, sino a una revisión del papel y de la importancia en términos de productividad eléctrica del propio sistema que ya para ese año, atendiendo al contexto nacional e incluso regional ya era muy baja. 
La controversia laboral que generó la extinción, el combativo papel que jugó el Sindicato Mexicano de Electricistas exigiendo la reinstalación de la antigua planta laboral, y las posibilidades que se auguraban ante la Reforma energética impulsada por el actual gobierno federal (20122018) dieron una segunda oportunidad a las instalaciones eléctricas de Necaxa, para seguir siendo utilizadas en la generación de energía eléctrica. Actualmente, toda la producción está destinada al Centro Nacional de Energía Eléctrica (CENACE) como suministro de urgencia ante fallos en la red general. Para ello, desde mediados de 2016 complejo hidroeléctrico de Necaxa fue concesionado por treinta años a la empresa Generadora Fénix, Sociedad Anónima Promotora de Inversión de Capital Variable (S.A. de P.I.C.V.). Dicha sociedad está formada por el Sindicato Mexicano de Electricistas (SME), con una participación del 49 por ciento del capital social, y la empresa portuguesa Mota-Engil, que posee el resto. Generadora Fénix gestiona catorce instalaciones que antes poseía LyFC, entre las que se encuentran las tres plantas del sistema de Necaxa (Tepexic, Necaxa y Patla). Así mismo controla y da mantenimiento al conjunto de embalses del Sistema hidroeléctrico de Necaxa.

A pesar de ese retorno a la actividad de generación de energía eléctrica el sistema estuvo inactivo casi siete años y ello hizo que unos pocos agentes políticos se movilizaran para darle un nuevo uso al gran recurso de la zona, el agua, aprovechando que en la región imperaba un grave problema laboral y socioeconómico derivado de la misma extinción de Luz y Fuerza de Centro (Belmont, 2013a; Campos Rubio, 2016). En este sentido, a nivel federal, la senadora Mónica T. Arriola Gordillo, en la LXII Legislatura del Congreso de la Unión, presentaba el 13 de noviembre de 2012, la proposición con Punto de Acuerdo, por el que se exhortaba al Ejecutivo Federal para que agilizara la elaboración y publicación del Plan de Manejo del Área Natural Protegida "Cuenca Hidrológica del Río Necaxa" y para que se verificase el cumplimiento de la NOM-SEMARNAT-1996 en la zona, con el objetivo principal de la conservación de esta Área Natural Protegida y asegurar la viabilidad de los proyectos de agua potable para el Valle de México. Dicha proposición fue turnada a la Comisión de recursos hidráulicos del Senado quién el 9 de abril 2013 emitió una resolución para que las áreas competentes del gobierno federal realizasen y publicasen el plan de manejo para la ANP y para que se determinasen los resultados de las estrategias de política pública aplicadas en el área (Senado, 2013). Siguiendo esa resolución, en 2013, la Comisión Nacional de Áreas Naturales Protegidas preesentaba el Estudio previo justificativo para la modificación de la declaratoria área de protección de recursos naturales Zona Protectora Forestal Vedada cuenca hidrográfica del río Necaxa, ubicada en los estados de Hidalgo y Puebla, México. En dicho trabajo se justificaba la ampliación 
de 643 hectáreas en el área natural protegida existente pertenecientes al municipio de Xicotepec, Puebla y la detracción de 161 hectáreas del poblado de Acaxochitlán en Hidalgo, dando como resultado un polígono de área natural protegida de 42,455 hectáreas o 424.55 kilómetros cuadrados (CONANP, 2013, p. 47-49).

En 2015, la Comisión Nacional del Agua (CONAGUA), a través de su programa de proyectos estratégicos propuso tres alternativas como nuevas fuentes de abastecimiento de agua para la Zona Metropolitana del Valle de México. Estas eran: Temascaltepec en la cuenca del Cutzamala, el Valle del Mezquital en el acuífero de Tula y las presas del Sistema Hidroeléctrico Necaxa. Respecto a éstas últimas, el proyecto contempla suministrar aproximadamente $12 \mathrm{~m}^{3} / \mathrm{s}$ al Valle de México de agua proveniente de las presas de Tenango, Nexapa, Necaxa, La Laguna y Los Reyes que conforman el Sistema Hidroeléctrico Necaxa (CONAGUA, 2015; Murrieta, Hernández, 2015; Luege, 2015). Se trata de un proyecto de abastecimiento de 131 kilómetros de longitud y que requeriría de 8 estaciones de bombeo y que en absoluto era novedoso pues al menos desde finales de la década de los setenta se habían desarrollado distintos proyectos en momentos diferentes (Aguilar, 1979; Intual, 1983; Carrera y Gaskin, 2009). Dichos proyectos, incluidos este de la CONAGUA, en caso de realizarse supondrían la cancelación de la producción eléctrica del sistema de Necaxa y conllevarían muy elevados costos. A pesar de ello, la crisis hidrológica que se vive en el Valle de México hace inevitable ese traslado en el medio plazo, y el hecho que la actividad de generación eléctrica esté en mínimos operativos por procesos relacionados por la gestión de la políticas energéticas mexicanas, abona la idea de que el agua está a un paso de convertirse en el recurso estratégico de la zona.

El mismo problema socioeconómico generado en la zona por la extinción de Luz y Fuerza del Centro, que insistimos supuso el despido masivo de los trabajadores de las plantas de Necaxa (Victoria, 2012; Belmont, 2013a y 2013b), sumado a la situación de alta marginación en la que desde hace décadas se encuentra toda la región de la Sierra Norte de Puebla, donde se ubica Necaxa, catalogada como una de las seis más severas de México (Quintana y García, 2000; Tovar, 2013), explicarían la aparición en el panorama de proyectos de reactivación económica de la cuenca de Necaxa, donde el turismo tiene cabida. En este sentido, no es baladí se haya otorgado la categoría de "Pueblos mágicos" a dos localidades de la cuenca de Necaxa: Xicotepec y Huachinango.

Sólo así, se puede entender el macro proyecto turístico en la zona, denominado "Proyecto turístico integral Necaxa" pensado por el Gobierno del Estado de Puebla. Mismo que en mayo de 2014 fue 
presentado para su análisis al Fondo Nacional del Fomento al Turismo (FONATUR) y que requería una inversión total de 500 millones de pesos a devengar en años venideros. Éste se desarrollaría en una extensión de 300 hectáreas $\left(3 \mathrm{~km}^{2}\right)$, aprovechando la presencia de los cuerpos de agua de los vasos de las presas de Tenango y Nexapa (dos de los cinco del Sistema hidroeléctrico de Necaxa) y el entorno natural de los mismos correspondiente a las localidades de Tenango de las Flores, Papatlazolco, Papatlatla y Xaltepec (Ánimas, 2015). El mencionado proyecto buscaba el desarrollo inmobiliario del área a similitud del Valle de Bravo, localidad turística del Estado de México y contaría con un campo de golf, un malecón, un club náutico, una zona hotelera, etc (Hernández, 2014; Ánimas, 2015; Quórum informativo, 2015).

A la fecha, no se conoce la situación del proyecto: pareciera que quedó stand by ante la celebración de elecciones a la gubernatura de Puebla y el cambio de gobierno estatal, aun cuando éste es continuista del anterior; o quizás los anunciados recortes en materia de infraestructura turística por parte del gobierno federal no lo hayan permitido prosperar; o bien que la inversión, difícilmente podría desarrollarse en el marco de un área natural protegida y representaría una grave amenaza al equilibrio ambiental del área como ya fue denunciado en diciembre de 2015 en el Foro Nacional de Cuacuila celebrado en Huauchinango; Puebla (Hernández, 2014; Ánimas, 2015; Quórum informativo, 2015).

\section{Hacia la consideración del sistema hidroeléctrico de Necaxa como paisaje cultural.}

A lo largo de este artículo, hemos expuesto de forma sucinta algunos de los aspectos clave que caracterizan ya la cuenca hidrográfica del río Necaxa, particularmente el área natural protegida "Zona forestal vedada", ya del sistema hidroeléctrico de Necaxa. Hemos hablado de los problemas que los afectan, y de los diferentes agentes que intervienen en su devenir, cada uno con sus intereses: desde las empresas que manejan la hidroeléctrica y mantienen las infraestructura actualmente; pasando por los extrabajadores de Luz y Fuerza del Centro, miembros activos del Sindicato Mexicano de Electricistas y que se vieron afectados por la liquidación de la empresa; siguiendo por los propios pobladores que tuvieron un papel fundamental en la historia del sistema hidroeléctrico y que quedaron marginados de ese entorno que contribuyeron a construir, hasta los agentes políticos (municipales, estatales, federales) que proponen y tratan de disponer, a su antojo, de este marco todavía inigualable que sigue siendo Necaxa.

La riqueza y belleza del entorno natural que acoge hoy el conjunto de las cinco represas que conforman el sistema hidroeléctrico, junto con el interés y valor histórico del patrimonio industrial eléctrico construido, se 
conjugan todavía en un entorno paisajístico de gran calidad. Esto pese a los problemas que hemos expuesto, en cuanto la pérdida de la calidad del medio acuático, la erosión acuciante y los problemas de movimientos de remoción en masa en laderas y pendientes, la pobreza extrema que caracteriza esta región...

Existen numerosos elementos que nos hablan de la historia iniciada hace ya cerca de 115 años y que fue moldeando un entorno para la producción eléctrica que hoy se ha naturalizado. Lejos quedan ya las más de 7,000 personas que estuvieron implicadas en su construcción, muchos de los cuales dejaron su vida en las obras, pero persiste en la memoria de los pobladores de Necaxa, Tenango, Xaltepec, Patoltecoya y otras más, la vinculación de sus familias con la construcción del sistema hidroeléctrico.

La riqueza del patrimonio construido no radica solamente en su antigüedad, sino en muchos aspectos: la belleza de su construcción visible en sus presas de núcleo de arcilla y de otros elementos construidos; su inserción en el entorno natural que lo acoge; también en la dimensión todavía humana que tiene el conjunto de la obra-a pesar del impacto que supuso para muchos de sus habitantes la inundación de sus casas y tierras de labor-y; finalmente, quizás lo más importante, que se trata de un patrimonio aún vivo, que produce energía, que conserva elementos del proceso de generación eléctrica de tiempos pasados, y que su funcionamiento permite seguir siendo seña y símbolo del movimiento obrero mexicano y del proceso de modernización del México de principios del siglo $X X$, cuando el alumbrado público y la fuerza motriz aplicada al transporte y a la producción industrial parecían resarcir el país de su pasmoso atraso.

Toda el área natural protegida con el nombre de Área de protección de recursos naturales Zona protectora forestal vedada "Cuenca hidrográfica del río Necaxa" y el Sistema hidroeléctrico de Necaxa debe ser considerada como paisaje cultural. Esta calificación ha de representar la oportunidad para el país de conjuntar la protección del patrimonio natural que está representado por el área natural protegida y la protección del patrimonio tecnológico e industrial del complejo hidroeléctrico. En última instancia, con esa denominación ganarán los pobladores de la cuenca en mejora de su calidad de vida y en oportunidades de trabajo, y gana México al conservarse elementos fundamentales para entender la historia reciente del país. 


\section{Referencias.}

Aguilar-Maldonado, Alexis. Methodology for long-term water supply planning: Mexico City case. A Dissertation Submitted to the Faculty of the Department of Hydrology and Water Resources in Partial Fulfillment of the Requirements for the Degree of Doctor of Philosophy with a major in Water Resources Administration in the Graduate College, The University of Arizona, 1979, 157 p.

Alvarado, Gabriela Victoria. La reconstrucción de la identidad y acción colectiva del trabajador electricista de Necaxa. Tesis de maestría en Estudios Sociales, México, Universidad Autónoma Metropolitana, Unidad Iztapalapa, 2012, 240 p.

Barrios Ordoñez, J. Eugenio; Martínez Cordero, Miguel Ángel; Jiménez Cisneros, Blanca; Lara Vázquez, Adolfo; Barocio Ramírez, Rubén; Franco Mariscal, José María. "Programa de manejo del sistema hidrológico de Necaxa. Diagnóstico, implementación y financiamiento", Federación Mexicana de Ingeniería Sanitaria y Ciencias Ambientales; AIDIS. Gestión inteligente de los recursos naturales: desarrollo y salud. México D.F: FEMISCA, 2002. p. 1-9. <http://www.bvsde.paho.org/ bvsaidis/mexico26/viii-009.pdf> [15 de octubre de 2016]

Bélgica Cerón-Carpio, A., Contreras-Jiménez, J.L., De Gante-Cabrera, V.H. "Inventario pteridoflorístico del área de protección de recursos naturales" Cuenca hidrográfica del río Necaxa", porción Puebla, México." Polibotánica, no 33, 2012, p. 41-55.

Belmont Cortés, Edgar Israel. "La transformación de la dinámica social en la comunidad electricista de Necaxa, Puebla: el uso de los recursos hidrológicos como campo de disputa", El Cotidiano, 2013a, vol. 182, p. 17.

Belmont Cortés, Edgar Israel. "La comunidad electricista de Necaxa (Puebla) tras el cierre de Luz y Fuerza del Centro: espacio social y marcos referenciales en juego", Intersticios Sociales, núm. 6, septiembre-febrero, 2013b, p.1-32.

Bobek, H, Grundfragen der Stadtgeographie. Geographische Anzeiger. Núm, 28, 1927, p. 213-224.

Bobek, H. y Schmithüsen, J. Die Landschaft in Logischen System der Geographie. Erdkunde, Vol. 3, núm. 2/3, Agosto de 1949, p. 112-120.

Brunhes, Jean. Géographie humaine. Essai de classification positive. Principes et exemples. Paris: Félix Alcan, 1910.

Cámara de Diputados. Transcripción del Foro sobre el desarrollo integral de la Cuenca de Necaxa convocado por la Comisión de Medio Ambiente y Recursos Naturales de la Honorable Cámara de Diputados, LX Legislatura, miércoles 28 de febrero de 2007, Dirección General de Crónica Parlamentaria de la Cámara de Diputados.

Campos Rubio, Jesús. "La terminación de políticas y organizaciones públicas. El caso de la extinción de Luz y Fuerza del Centro en México", Gestión y Análisis de Políticas Públicas, Núm. 15, 2016. 
Campos Vega, Juan. Exitosas huelgas de electricistas y obreros agrícolas en 1936. Estudios Políticos, Sociales e Históricos, Vida y Obra de Vicente Lombardo Toledano, 19 Septiembre de 2014. [Consultado en 5 de julio de 2019]. <https:// www.centrolombardo.edu.mx/exitosas-huelgas-de-electricistas-y-obrerosagricolas-en-1936/>.

Centro de Estudios de las Finanzas Públicas, CEFP. Proyecto de presupuesto de egresos de la federación 2015: Recursos identificados para el estado de Puebla. México DF: Centro de Estudios de las Finanzas Públicas. LXII Legislatura, Cámara de Diputados, octubre de 2015.

Carrera-Hernández, Jaime J.; Gaskin, S. J. "Water management in the Basin of Mexico: current state and alternative scenarios", Hydrogeology journal, vol. 17, no 6, 2009, p. 1483-1494.

Chamoux, Marie-Noëlle, Nahuas de Huauchinango: transformaciones sociales en una comunidad campesina, Ciudad de México, Instituto Nacional Indigenista; Centre d'Etudes Mexicaines et Centramericaines, 1987, 388 p.

Checa-Artasu, Martín M.; Sunyer, Pere; Coello, José Francisco. “De lo indispensable a lo incómodo. El sistema hidroeléctrico de Necaxa (México) (1895-2016) como paisaje cultural." Zaar, Miriam H.; Vasconcelos Pedro. Junior, Magno; Capel, Horacio (Eds.). La electricidad y el territorio. Historia y futuro. Barcelona, Universidad de Barcelona/Geocrítica, 2017.

Checa-Artasu, Martín M.; Sunyer, Pere."Los valores de un paisaje industrial emblemático de México, el Sistema Hidroeléctrico de Necaxa, Puebla." Gremium, Vol. 6, Núm.2 (6), 2019.

Comisión Nacional del Agua (CONAGUA). Proyectos estratégicos. Agua potable, drenaje y saneamiento. [Presentación PPT] Subdirección de agua potable, drenaje y saneamiento, Comisión Nacional del agua, Febrero de 2015. $<$ http://islaurbana.mx/wp-content/uploads/2015/10/Proyectos-estrategicosCONAGUA-Febrero-2015.pdf> [5 de octubre de 2016]

Comisión Nacional de Áreas Naturales Protegidas (CONANP). APRN Cuenca Hidrográfica del Río Necaxa. [Web]. Dirección de la Región Planicie Costera y Golfo de México, Comisión Nacional de Áreas Naturales Protegidas, 28 de abril de 2011. <http://regiongolfodemexico.conanp.gob.mx/rionecaxa.php\#. V9cGqljhCCg> [10 de octubre de 2016]

Comisión Nacional de Áreas Naturales Protegidas (CONANP). Estudio previo justificativo para la modificación de la declaratoria área de protección de recursos naturales Zona Protectora Forestal Vedada cuenca hidrográfica del río Necaxa, ubicada en los estados de Hidalgo y Puebla, México. 2013, 121 p. <https://issuu.com/ antoniozone/docs/epj_aprn_necaxa_22_abril_2013_bis> [15 de octubre de 2016]

Comisión Nacional de Áreas Naturales Protegidas (CONANP). Cuenca Hidrográfica del Río Necaxa, Ficha SIMEC. Comisión Nacional de áreas naturales protegidas, agosto de 2016. <https://simec.conanp.gob.mx/ficha.php?anp=117\&=11>[21 de octubre de 2016] 
Consejo de cuenca de los ríos Tuxpan al Jamapa. Informe de actividades del consejo de cuenca de los ríos Tuxpan al Jamapa, 2015, 53p. <http://www. consejocuencatuxpanjamapa.org/informes/INFORMETJ2015.pdf> $[15$ de octubre de 2016]

D.O.F. (Diario Oficial de la Federación). Decreto que declara Zona Protectora Forestal Vedada, los terrenos que limita la cuenca hidrográfica del río Necaxa. 20 de octubre de 1938. p. 11- 15. <https://simec.conanp.gob.mx/pdf decretos/117 decreto.pdf> [15 de octubre de 2016]

D.O.F. (Diario Oficial de la Federación). Acuerdo por el que se determina como área natural protegida de competencia federal, con la categoría de área de protección de recursos naturales, la Zona Protectora Forestal Vedada Cuenca Hidrográfica del río Necaxa, establecida mediante decreto publicado el 20 de octubre de 1938. 9 de septiembre de 2002. <https://simec.conanp.gob.mx/pdf recategorizacion/117_reca.pdf $>$ [15 de octubre de 2016].

Dorn, Harold. "Hugh Lincoln Cooper and the First Détente", Technologies and Culture. Vol. 20. Núm. 2. Abril, 1979. p. 322-347

Flores Guerrero, Efraín. Sistema de represas y corredores biológicos de la cuenca hidrográfica del río Necaxa. Ficha Informativa de los Humedales de Ramsar (FIR), 2008.

Luz y Fuerza del Centro, Comisión Nacional del Agua y Gobierno del Estado de Puebla. Estudio del Saneamiento Integral de las principales localidades comprendidas dentro del Sistema Hidrológico de Necaxa en los Estados de Puebla e Hidalgo. México DF: Instituto de Ingeniería, Universidad Nacional Autónoma de México, 2000.

García Espinosa de los Monteros, Catalina. "El patrimonio industrial como objeto cultural. El caso de la hidroeléctrica Necaxa.", Álvarez Areces, Miguel Ángel (coord.) Patrimonio inmaterial e intangible de la industria: artefactos, objetos, saberes y memoria de la industria. 2012, p. 265-274

García Espinosa de Los Monteros, Catalina. “Complejo Hidroeléctrico Necaxa. Territorio, Identidad y Patrimonio.", Geografia Ensino \& Pesquisa, vol. 19, 2015, p. 37-47.

García Espinosa de Los Monteros, Catalina. Patrimonialización y constitución socio-técnica. El Complejo Hidroeléctrico Necaxa como dispositivo reticular. Tesis Doctoral. Dirección Dr. Andoni Ibarra. Donostia: Universidad del Pais Vasco/ Universidad Carlos III de Madrid/ Universidad Nacional Autónoma de México, 2017, 386 p.

Gómez-Tagle, Silvia y Miquet, Marcelo. Integración o democracia sindical: El caso de los electricistas. Tres estudios sobre el movimiento obrero en México, México: El Colegio de México, 1976.

Guadarrama, A.; Páez Vieyra, J.,"Complejo hidroeléctrico de Necaxa: criterios para su valorización y conservación como sitio de patrimonio industrial." Oviedo, Belem; Dorel-Ferré, Gracia (Comp.).Patrimonio Industrial y Desarrollo Regional. Rescate, Valorización, Reutilización y Participación Social. Pachuca: Archivo Histórico y Museo de Minería, A. C.; TICCIH México, A. C., febrero 2015, p. 325-354 
Hofmeister, Burkhard. The study of urban form in Germany. Urban Morphology, 2004. Vol. 8. Núm. 1. p. 3-12.

Intual. Intercambio y reuso de aguas en el valle de México como fuente alternativa de abastecimiento de agua potable a la Z.M.C.M. y su comparativo con las otras fuentes Secretaria de Desarrollo Urbano y Ecología, 1983.

Martínez Miranda, E. A.; Ramos Lara, M. de la Paz. "La física y la formación de los ingenieros mexicanos que colaboraron en el magno proyecto hidroeléctrico de Necaxa", Revista Mexicana de Física, vol. 51, núm. 1, junio, 2005, p. 37-44.

Martínez Miranda, Elio Agustín; Ramos Lara, Ma. De La Paz. "Primer intento de construcción de la planta hidroeléctrica de Necaxa." Boletín de monumentos históricos. Tercera época. Instituto Nacional de Antropología e Historia (INAH). Núm. 33. Enero-Abril. 2015. p. 50-62

Martínez Miranda, E. A.; Ramos Lara, M. de la Paz. "Las obras hidroeléctricas de Necaxa realizadas por The Mexican Light and Power Company, Limited, Periodo 1903-1921." Sunyer, Pere; Ribera, Eulalia; Checa-Artasu, Martín; Moncada, J. Omar (eds.). Actas del III Simposio Internacional Historia de la electrificación. Estrategias y cambios en el territorio y en la sociedad. Ciudad de México, 17 al 20 de marzo de 2015. Barcelona: Universidad de Barcelona, 2015. Disponible en: <http://www.ub.edu/geocrit/iii-mexico/miranda.pdf>

Montiel Rosado, José Arturo. “El Sistema Hidroeléctrico de Necaxa, patrimonio eléctrico de Latinoamérica", Revista Conectate, Vol. I, Núm. 35, Septiembre 2008.

Mora, Libertad, coord., Huauchinango: el rumor del tiempo. Huauchinango: Perspectivas interdiscipliarias en red, AC, 2011, 373 p.

Murrieta, Felipe de Alba; Hernández Guerrero, Natalia. “El agua en la impronta contemporánea: un debate urgente", Centro de Estudios Sociales y de Opinión Pública Documento de Trabajo, núm. 191. Mayo de 2015, México DF: Cámara de Diputados/LXII Legislatura.

Niembro Rocas, Silvia María. Atención de un incendio forestal en el Área de Protección de Recursos Naturales Zona Forestal Vedada Cuenca Hidrográfica del Rio Necaxa en el Estado de Puebla. Informe final SNIB-CONABIO, proyecto No. MR001.Comisión Nacional de Áreas Naturales Protegidas; Secretaría de Medio Ambiente y Recursos Naturales, 2014, 15 p.

Ojeda Capella, Arcadio; De la Maza Elvira, Roberto. Estudio justificativo para el rescate y operación del decreto del Área de Protección de Recursos Naturales Cuenca del Río Necaxa, expedido por el Ejecutivo Federal en 1938. Documento digital entregado a la CONANP, 2001, 20 p.

Oropesa, Gabriel. Las obras hidroeléctricas de Necaxa. Memorias de la Sociedad Científica "Antonio Alzate", 1917-1920, XXXVII, pp. 249-266.

Ortega Morel, Javier, "El Sistema Hidroeléctrico de Necaxa: extraordinario patrimonio industrial eléctrico en operación.", Patrimonio universal, Consejo mexicano para la conservación del patrimonio industrial, núm. 7, noviembre 2000. 
Partzsch, D. Zum Begriff der Funktionsgesellschaft. Mitteilungen des Deutschen Verbandes fuer Wohnungswesen, Staedtebau und Raumplannung, 1964, IV, pp. 3-10.

Pearson, F. S; Blackwell, F. O. The Necaxa Plant of the Mexican Light and Power Company. Transactions of the American Society of Civil Engineers, LVIII (Paper 1.040),1907, pp. 37-50.

Peña Guzmán, Celina. "La Hidroeléctrica de Necaxa y la Mexican Light and Power Co., patrimonio industrial en riesgo", Labor \& Engenho, vol.5, n², 2011.

Peña Guzmán, Celina. "Frederick Stark Pearson y la construcción de la hidroeléctrica de Necaxa." Casals, Vicente; Capel, Horacio (eds.). Actas del Simposio Internacional Globalización, innovación y construcción de redes técnicas urbanas en América y Europa, 1890-1930. Brazilian Traction, Barcelona Traction y otros conglomerados financieros y técnicos. Barcelona, 23-26 de enero de 2012. Barcelona: Universidad de Barcelona, 2012.

Peña Guzmán, Celina; Santander Soto, Gissel. “Nos quitaron la luz pero no la fuerza: La resistencia ciudadana y la memoria colectiva del pueblo de Necaxa y del Sindicato Mexicano de Electricistas ante el decreto de extinción de Luz y Fuerza del Centro", Zaar, Miriam H.; Vasconcelos Pedro. Junior, Magno; Capel, Horacio (Eds.). La electricidad y el territorio. Historia y futuro. Barcelona, Universidad de Barcelona/Geocrítica, 2017.

Pérez Téllez, Iván, El inframundo nahua a través de su narrativa. Ciudad de México, Instituto Nacional de Antropología e Historia, 2014, 112 p.

Quintana, Roberto Diego; García, María Tarrío. “Canasta del financiamiento rural: el caso de tres comunidades indígenas de la región de Huauchinango", Nueva Antropología, vol. 17, Núm.58,2000, p. 123-140.

Redfield, Robert. Tepoztlan, a Mexican Village. Chicago: Chicago University Press, 1930.

Redfield, Robert. Cultural Changes in Yucatan. American Anthropologist. 1933. Vol. 36. p. 57- 69.

Ricárdez Cabrera, M. M. “La revaloración cultural a través de la identificación de relaciones socioambientales en paisajes hídricos, Sierra norte de Puebla, México." Congresos de Epistemópolis. Congreso Internacional de Ciencias Sociales, $2018<$ https://conferences.epistemopolis.org/index.php/cienciassociales/ CS2018/paper/view/4777> [30 de octubre de 2018]

Ríos Sais, Gerardo. Cambio climático y gestión de áreas Naturales protegidas (Medir la tasa y patrones de cambio de la vegetación natural a través del empleo de imágenes de satélite, en el APRN Cuenca Hidrográfica Río Necaxa, para obtener una línea base del estado actual de su cobertura forestal respecto a los usos del suelo en cada área, para establecer sitios prioritarios para la conservación, como herramienta de monitoreo y para la toma de decisiones.) Informe Final Cuenca Hidrográfica del Río Necaxa. Comisión Nacional de Áreas Naturales Protegidas, Deutsche Gesellschaft für Internationale Zusammenarbeit (GIZ) GmbH. Proyecto Cambio Climático y Gestión de Áreas Naturales Protegidas (CCyANP), 2012, 67 p. <https://simec.conanp.gob.mx/pdf_evaluacion/necaxa.pdf> [15 de octubre de 2016] 
Romero Rodríguez, Javier, Necaxa cuna de la industria eléctrica, México, Fundación Necaxa Cuna de la industria eléctrica A.C., 2010.

Romero Rodríguez, Javier, "Necaxa, patrimonio industrial de México y del mundo". Labor e Engenho, Núm. 6(4), 2012, p.11-20.

Ruelas Monjardín, Laura C.; Olivo Escudero, Juan Carlos; Rodríguez Ávila, Verónica. Programa para la gestión integral de la subcuenca del río Necaxa. El Colegio de Veracruz, 2016.

Ruppert, K.; Schaffer, F. La Polémica de la Geografía Social en Alemania(I): sobre la Concepción de la Geografía Social. Geocrítica. Cuadernos críticos de Geografía Humana. Universidad de Barcelona. IV (21), mayo de 1979

Sala Catalá, José. La localización de la capital de la Nueva España, como problema científico y tecnológico. Quipu. Vol. 3, núm. 3, septiembre-diciembre de 1986, p. 279-297.

Sauer, Carl (1925). The Morphology of Landscape. Berkeley: University of California Press, p. 19-53. Edición utilizada J. Leighly (Ed.) (1963) Land and Life: A Selection of Writings of Carl Orwin Sauer. Berkeley: Univ. of California Press, p. 315-350.

Senado de la República. Dictamen la proposición con Punto de Acuerdo que exhorta al Ejecutivo Federal para que agilice la elaboración y publicación del Plan de Manejo del Área Natural Protegida "Cuenca Hidrológica del Río Necaxa" y verifique el cumplimiento de la NOM-SEMARNAT-1996 en la zona, con el objetivo principal de la conservación de esta Área Natural Protegida y asegurar la viabilidad de los proyectos de agua potable para el Valle de México, 9 de abril de 2013. <http://sil. gobernacion.gob.mx/Archivos/Documentos/2013/04/asun_2967740_20130416 1366122543.pdf> [1 de octubre de 2016]

Sunyer Martín, Pere. Paisajes para todos. De la valorización del paisaje a su sensibilización. En: Martín Checa-Artasu; Pere Sunyer Martín (Coords.). El paisaje: reflexiones y métodos de análisis. México: Universidad Autónoma MetropolitanaIztapalapa/ del Lirio, 2017, p. 21-44.

Sunyer Martín, Pere. Forma y función en la geografia. Aplicaciones al estudio del paisaje. Colegio Michoacán. 2020 (En publicación).

Tovar, Elsa Patiño. "Territorio, pobreza y vida en el estado de Puebla", LiminaR. Estudios Sociales y Humanísticos, vol. 1, Núm. 2, 2013, p. 43-58.

Universidad Autónoma de Chapingo (UACHA); Instituto Nacional de Ecología (INECOL). Estudio de ordenamiento ecológico territorial de las cuencas hidrológicas de los ríos Necaxa y Laxaxalpan. México DF: Secretaria de Medio Ambiente y Recursos Naturales. Instituto Nacional de Ecología. Universidad Autónoma Chapingo, 2003.

Valencia Valera, Víctor Hugo; Mellado May Lesly, Huauchinango: haciendo su historia. Ciudad de México, Instituto Nacional de Antropología e Historia, 2005,235 p. 
WH Committee (1992). Revision of the operational guidelines for the implementation of the World Heritage Convention (whc-92/conf.002/10/Add). Paris, World Heritage Committee. <whc.unesco.org/archive/1992/WHC-92CONF002- 10Adde.pDf>.

WH Committee (1999). Operational guidelines for the implementation of the World Heritage Convention. Paris: WHC. 99/2. March.

Whitehand, J. W. R.; Larkham, P. Urban Landscapes: international perspectives. Psychology Press, 1992, 333 p.

Ánimas Vargas, Leticia. "Cuestiona especialista trabajo de Silvia Niembro al frente de la APRN", Municipios, 2 de marzo de 2014 (a). <http://municipiospuebla. $\mathrm{mx} /$ nota/2014-03-02/huauchinango/cuestiona-especialista-trabajo-de-silvianiembro-al-frente-de-la-aprn> [15 de octubre de 2016]

Ánimas Vargas, Leticia. “Destituyen a Silvia Niembro de la Dirección del APRNNecaxa", Municipios, 5 de agosto de 2014 (b). <http://municipiospuebla. $\mathrm{mx} /$ nota/2014-08-05/huauchinango/destituyen-silvia-niembro-de-ladirecci\%C3\%B3n-del-aprn-necaxa> [15 de octubre de 2016]

Ánimas Vargas, Leticia. "Estado alienta zona turística de lujo en presas de Huauchinango", Municipios, 16 de agosto de 2015. <http://municipiospuebla.com. $\mathrm{mx} /$ nota/2015-08-16/huauchinango/estado-alienta-zona-tur\%C3\%ADstica-delujo-en-presas-de-huauchinango> [15 de octubre de 2016]

Luege Tamargo, José Luis (2015). “Necaxa, agua para la ciudad”, El Universal, 14 de septiembre de 2015. <http://www.eluniversal.com.mx/entrada-de-opinion/ articulo/jose-luis-luege-tamargo/metropoli/2015/09/14/necaxa-agua-para-laciudad> [15 de octubre de 2016]

Quórum informativo. “Declaran a la Sierra Norte de Puebla, Territorio libre de Megaproyectos de Muerte", Biodiversidad en América latina y el Caribe [web], 28 de diciembre de 2015. <http://www.biodiversidadla.org/Principal/Secciones/ Noticias/Mexico_Declaran_a_la_Sierra_Norte_de_Puebla_Territorio_libre_de Megaproyectos de Muerte> [15 de octubre de 2016]

Ramírez Cabrera, Víctor Florencio. "Cuenca del Necaxa: ilegalidad y malas decisiones", SDPnoticias.com [web].13 de febrero de 2014. <http://www. sdpnoticias.com/columnas/2014/02/13/cuenca-del-necaxa-ilegalidad-y-malasdecisiones> [15 de octubre de 2016] 